\title{
ДИХОТОМИЯ СТРУКТУРНОЙ ТРАНСФОРМАЦИИ ЭКОНОМИКИ И МАКРОЭКОНОМИЧЕСКОЙ НЕСТАБИЛЬНОСТИ
}

\author{
(c) 2020 Каячева Людмила Викторовна \\ кандидат экономических наук, доцент, кафедра «Финансы и управление рисками» \\ Сибирский федеральный университет, Россия, Красноярск
}

\author{
(c) 2020 Слесаренко Екатерина Владимировна \\ старший преподаватель, кафедра «Финансы и кредит» \\ Кузбасский государственный технический университет им. Т. Ф. Горбачева, Россия, Кемерово \\ E-mail:sev.fk@kuzstu.ru
}

В статье обоснована дихотомия структурной трансформации экономики и макроэкономической нестабильности, которые, находясь в причинно-следственной взаимосвязи, попеременно выступают стабилизирующе-дестабилизирующими силами, как применительно к структурным пропорциям в экономике, так и к ее динамике на макроуровне. Установлено, что макроэкономическая нестабильность в российских условиях ввиду отстраненности государства от проведения структурной политики, направленной на преодоление изменений дегенеративного характера, имеет структурную обусловленность. Представленные сценарии протекания структурно-индуцированной макроэкономической нестабильности, определяют ее как Ү-дестабилизацию с риском перехода в L-дестабилизацию.

Ключевые слова: дихотомия, структурно-индуцированная макроэкономическая нестабильность, воспроизводственные проблемы, внешние шоки

Незавершенный процесс рыночных преобразований в российской экономике, накапливание в ней структурных диспропорций, макроэкономическая нестабильность в условиях нарастания социально-экономического и технологического отставания от передовых стран мира требуют комплексного исследования трансформации основы национального хозяйства - структуры экономики,- с учетом ее взаимного влияния на процессы макроэкономической динамики. Однако, если относительно определения структуры экономики как совокупности различных тесно связанных и взаимозависимых элементов, находящихся в определенных пропорциях относительно друг друга, в среде ученых (С. Ю. Глазьев [5], О. Ю. Красильников [8], О. С. Сухарев [11] и др.) сложился определенный консенсус, то исследование структурной трансформации пока не получило должной методологической основы, в частности, позволяющей определить характер ее связи с особенностью протекания нестабиль- ности в российской экономике.

Зачастую связь структурной трансформации и макроэкономической нестабильности в экономической науке определяется через стихийную или регулируемую адаптацию экономики к энтропии и нестабильности мирового рынка (С.Амин [1], Ф.Лист [9] и др.); трансляцию рыночной неопределенности, зарождающейся на макроуровне в мезо- и микроуровневые процессы ценообразования, распределения ресурсов и доходов (Б.Гильдебранд [4], Дж.Б.Кларк [7] и др.); кризисы перепроизводства и переинвестирования, зарождающиеся в ходе долгосрочных трансформаций структуры воспроизводства (пропорции сбережения, накопления и инвестирования капитала) и выступая триггерами наиболее существенных проявлений макроэкономической нестабильности - циклических кризисов (Дж.М. Кейнс [6], Дж.Р.Хикс [12] и др.). Или же через дестабилизацию экономики в краткосрочном периоде в условиях масштаб- 
ных технологических изменений и адаптации к ним отраслевых субъектов (М.А.Гасанов [3], Й.А.Шумпетер [13] и др.).

Наиболее близки нам выводы сторонников, представляющих структурную трансформацию в двух преобразованиях: постепенных - в сфере отношений собственности, воспроизводства, и быстрых - технологических, рыночноотраслевых пропорций (Ф.Перру [10], Р. Барр [2] и др.). Такие многоуровневые всеохватывающие структурные изменения приводят к появлению новых отраслей и кластеров, к исчезновению старых, развитию одних и депривации других видов экономической деятельности, в результате чего возникают значительные шоки спроса и предложения, занятости и доходов, цен и инвестиций (изменение макроэкономических переменных).

Между тем, структурный сдвиг как форма трансформации преимущественно определяется учеными в качестве источника дестабилизации на макроуровне, зачастую, безотносительно его регулирования, что формирует стихийный характер структурных изменений, проявляясь в экономике деградационно. В нашем представлении структурная трансформация неотделима от инициирующих и регулирующих ее сил, то есть от государственной структурной политики, подразумевая при этом под собой целый комплекс взаимосвязанных качественных и количественных изменений, направленных на повышение конкурентоспособности национальной экономики, улучшение благополучия населения за счет преодоления негативного структурного сдвига и отрицательной макроэкономической динамики.

В таком представлении структурная трансформация состоит в неразрывной причинноследственной связи с макроэкономической нестабильностью. С одной стороны, структурная трансформация с характерным увеличением долей сектора высокотехнологичных услуг, обрабатывающих и высокотехнологичных отраслей, автономных инвестиций, инновационноактивных социальных групп, неизбежно вызывает дестабилизацию экономики в кратко- или среднесрочном периоде, так как при- водит к перераспределению инвестиций, доходов, ресурсов, изменению места национальной экономики в глобальных производственных цепочках. Однако по мере обретения структурой экономики нового качества повышается защищенность экономики к дестабилизирующим процессам, которые также имеют структурную природу (спад промышленного производства и банкротства субъектов рынка, ускорение инфляции издержек и стагнации инвестиций). С другой стороны, структурная трансформация, определяемая технологической примитивизацией промышленности и ростом доли сырьевых производств, усилением монополий, упрощением экспорта, усиливает подверженность экономики дестабилизирующим процессам, с характерной волатильностью макроэкономических индикаторов выпуска, занятости, цен.

Положив в основу двойственную причинноследственную связь структурной трансформации и макроэкономической нестабильности, мы определяем ее как дихотомическую. Такая дихотомическая связь проявляется в том, что структурная трансформация экономики выступает источником макроэкономической нестабильности и вместе с тем оказывает на нее сдерживающее или усиливающее влияние, в зависимости от своего характера (регулируемый характер структурной трансформации оказывает сдерживающее, стабилизирующее воздействие на экономику, поступательно выводя экономические отношения на качественно новый уровень; стихийная - дестабилизирующее воздействие). Мы выводим это из противоречивой связи между структурной трансформацией и макроэкономической нестабильности, содержащей противоречие количества (показатели макроэкономической динамики, их стабильность или волатильность) и качества (структурные пропорции экономики).

Дихотомия структурной трансформации и макроэкономической нестабильности определяет качество последней, исходя из причин возникновения: рыночно-индуцированная и структурно-индуцированная макроэкономическая нестабильность.

Рыночно-индуцированная макроэкономиче- 
ская нестабильность, вызванная свойственной рынку неопределенностью в протекании микро-, мезоуровневых (единичные и отраслевые спрос и предложение на ресурсы и готовый продукт, цены, процентные ставки, потребительские предпочтения и ожидания инвесторов) и макроуровневых (совокупный спрос и предложение, эффективность факторов производства, тенденции глобального рынка) процессов.

Структурно-индуцированная макроэкономическая нестабильность - результат цепного характера соединения воспроизводственных проблем, трансляции внешних шоков в национальную экономику и ее негативных структурных изменений, которые вызывая дегенеративные трансформации макроэкономических пропорций, порождают диспропорции вовлечения факторов производства и ресурсов в народно-хозяйственный оборот, деградацию технологий и воспроизводства, определяя снижение производительности труда. Все это, в конечном итоге, суммируется в росте волатильности макроэкономических показателей, складывающейся в рецессивный тренд, который, по сути, есть результат реализации принципов и действия факторов структурной трансформации, и одновременно причина ухудшения структурных пропорций экономики.

Негативный тренд основных макроэкономических показателей в российской экономике проявлял себя на протяжении всего постсоветского периода (слабоотрицательная или «околонулевая» динамика физического объема ВВП, снижение реальных располагаемых денежных доходов населения, производительности труда и др.). Представленные тенденции происходили на фоне дегенеративных изменений в структуре экономики, что проявлялось в технологической примитивизации промышленного производства, росте доли низкотехнологичных услуг в третичном секторе, кризисе автономных инвестиций, упрощении экспорта, монополизации экономики, свидетельствуя о структурной обусловленности макроэкономической нестабильности.

Однако даже при самых благоприятных сценариях постпандемийного восстановле- ния российской экономики мы полагаем очевидным наличие признаков дестабилизации в 2020-2021 гг. и высокие их ожидания на 20222036 гг., которые в условиях сохранения старых (торговые войны, конъюнктурные колебания на мировом рынке энергоресурсов, финансовом рынке, санкционное давление, технологические «шоки») и возникновения новых внешних вызовов на фоне затягивания структурных реформ и улучшения институтов бизнеса, могут предопределить наступление структурного кризиса.

Опираясь на динамику основных макроэкономических и структурных показателей, а также изучив прогнозы восстановления российской экономики, представленные Минэкономразвития, Министерством финансов и ЦБ РФ, основываясь на классификации рецессивных процессов в экономике «LUVW», впервые представленной в отчете WPP Group в 2010 г. нами были выделены следующие возможные сценарии протекания структурно-индуцированной макроэкономической нестабильности в национальной экономике:

Сценарий «U-дестабилизация» определяется краткосрочным характером, в основе которого незначительные макроэкономические колебания, вызванные, прежде всего, экзогенными факторами спроса и предложения ресурсов и готового продукта, внешними шоками. При принятии своевременных государственных мер, способствующих увеличению темпов структурных изменений в экономике и быстрой адаптации к действию внешних вызовов, U-дестабилизация может смениться позитивным трендом устойчивого характера.

Сценарий «W-дестабилизация» характеризуется снижением ВВП в пределах 1,5-2\% в течение 2-3 лет, затем при благоприятной внешнеэкономической конъюнктуре может наблюдаться некоторое оживление, которое, между тем, не будет иметь долгосрочного характера без улучшения условий структурной трансформации экономики на основе существенного роста инвестиций, государственных расходов и улучшения институциональной среды. Данный вид дестабилизации представляет собой пассивную адаптацию экономики к экзогенным и эндоген- 
ным факторам при неизменном курсе государственной политики.

Сценарий «Ү-дестабилизация» характеризуется значительным спадом ВВП, уходя в отрицательный тренд в течение нескольких лет подряд, вызванным влиянием отрицательного структурного сдвига при фактическом отсутствии регулируемых трансформаций, усиливающих свой негативный эффект возникающими внешними шоками. Данный вид дестабилизации несет в себе риски перехода в рецессию, а затем и в стагнацию с более глубоким спадом, неизбежно ухудшая условия структурной трансформации. Для ее преодоления требуется выработка специальной государственной политики, направленной на создание условий для структурной трансформации за счет регулируемых структурных сдвигов и разработки системной защиты от внешних шоков в системе воспроизводства.

Сценарий «L-дестабилизация», переходящая в рецессию, представляет собой более глубокий и затяжной спад макроэкономических показателей. Именно данный вид дестабилизации сопряжен с долгосрочным отрицательным макроэкономическим трендом, инициированным затяжным характером отрицательного структурного сдвига в условиях отсутствия управля- емых трансформаций на фоне не слабеющих внешних шоков. Данный вид макроэкономической нестабильности несет в себе опасность наступления структурного кризиса, угрожая национальной экономике безвозвратным отставанием от передовых стран мира в уровне социально-экономического развития.

Процессы, протекающие в российской экономике, мы определяем как Ү-дестабилизацию, переходящую в дестабилизацию, которая при усилении старых и возникновении новых внешних шоков в условиях недостаточно эффективной антирецессивной политики государства, а также отсутствия регулируемых структурных трансформаций может перерасти в L-дестабилизацию, неся в себе опасность наступления структурного кризиса. С другой стороны, повышение технологического уровня, улучшение институциональной среды и воспроизводственных условий функционирования экономики как результата регулируемого структурного сдвига при одновременной выработке долгосрочных мер по защите от внешних шоков будет способствовать переходу дестабилизации в W-дестабилизацию, а затем и в U-дестабилизацию, создавая основу для долгосрочного стабильного экономического роста.

\section{Библиографический список}

1. Амин С. Вирус либерализма. Перманентная война и американизация мира / пер. с англ. Ш. Нагиба, С. Кастальского.-М.: Издательство «Европа», 2007. 168 с.

2. Барр Р. Политическая экономия: в 2-х т.: Т. 1: пер. с фр.- М.: Международные отношения, 1995.752 с.

3. Гасанов М.А., Гасанов Э. А. Структурная конвергенция в экономике России и ее ограничения // Вестник Томского государственного университета. Экономика. 2014. № 1 (25). С. 5-17.

4. Гильдебранд Б. Политическая экономия настоящего и будущего: Пер. с нем.- М.: Книжный дом «Либроком», 2012. 279 с.

5. Глазьев С.Ю. О задачах структурной политики в условиях глобальных технологических сдвигов. Часть 1 // Экономическая наука современной России. 2017. № 3. С. 31-43.

6. Кейнс Дж. М. Общая теория занятости, процента и денег. Избранное.- М.: Эксмо, 2007. 960 с.

7. Кларк Дж. Б. Распределение богатства. Пер. с англ.-М.: Экономика. 1992. 242 с.

8. Красильников О. Ю. Проблемы структурных преобразований в экономике // Экономист. 2001. № 8. С. $56-71$.

9. Лист Ф. Национальная система политической экономии: Пер. с нем.- М.: Издательство «Европа», 2005. 382 c.

10. Перру Ф. Экономика XX века.-М.: Экономика, 2000. 326 с.

11. Сухарев О.С. К разработке комплексной методики анализа структурных сдвигов в национальной экономике // Национальные интересы: приоритеты и безопасность. 2013. № 13 (202). С. 56-64. 
12. Хикс Дж. Р. Стоимость и капитал.- М.: Прогресс, 1993. 488 с.

13. Шумпетер Й. А. Теория экономического развития. Капитализм, социализм и демократия.- М.: Экономика, 1995.540 c. 